\title{
Major perioperative morbidity does not affect long-term survival in patients undergoing esophagectomy for cancer of the esophagus or gastroesophageal junction.
}

\author{
Brent T Xia \\ Thomas Jefferson University \\ Ernest L Rosato \\ Thomas Jefferson University \\ Karen A Chojnacki \\ Thomas Jefferson University \\ Albert G. Crawford

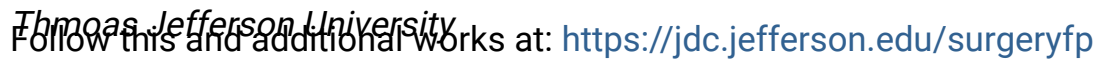 \\ iplaytheksteryurgery Commons

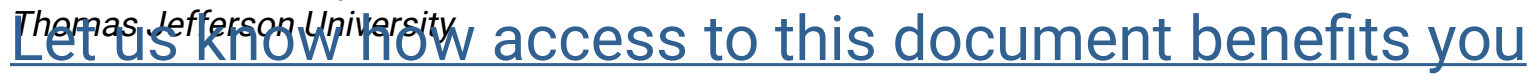

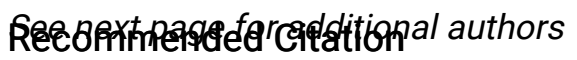

Xia, Brent T; Rosato, Ernest L; Chojnacki, Karen A; Crawford, Albert G.; Weksler, Benny; and Berger, Adam C., "Major perioperative morbidity does not affect long-term survival in patients undergoing esophagectomy for cancer of the esophagus or gastroesophageal junction." (2013). Department of Surgery Faculty Papers. Paper 115.

https://jdc.jefferson.edu/surgeryfp/115

This Article is brought to you for free and open access by the Jefferson Digital Commons. The Jefferson Digital Commons is a service of Thomas Jefferson University's Center for Teaching and Learning (CTL). The Commons is a showcase for Jefferson books and journals, peer-reviewed scholarly publications, unique historical collections from the University archives, and teaching tools. The Jefferson Digital Commons allows researchers and interested readers anywhere in the world to learn about and keep up to date with Jefferson scholarship. This article has been accepted for inclusion in Department of Surgery Faculty Papers by an authorized administrator of the Jefferson Digital Commons. For more information, please contact: JeffersonDigitalCommons@jefferson.edu. 


\section{Authors}

Brent T Xia, Ernest L Rosato, Karen A Chojnacki, Albert G. Crawford, Benny Weksler, and Adam C. Berger 


\section{Major Perioperative Morbidity Does Not Affect Long-Term Survival in Patients Undergoing Esophagectomy for Cancer of the Esophagus or Gastro-Esophageal Junction.}

Brent T. Xia, B.S., Ernest L. Rosato, MD, FACS, Karen A. Chojnacki, MD, FACS, Albert G. Crawford, PhD, Benny Weksler, MD, FACS, Adam C. Berger, MD

From the Department of Surgery, Thomas Jefferson University, Philadelphia, PA.

Correspondence: Adam C. Berger, 1100 Walnut Street, MOB, Suite 500; Philadelphia, PA 19147; Telephone-(215)955-1622; Fax-(215)923-8222; email-adam.berger@ jefferson.edu

Key words — esophageal cancer, perioperative morbidity; prognosis

Running Title: Morbidity does not affect survival after esophagectomy 


\section{ABSTRACT}

Introduction: The incidence of cancer of the esophagus/GE junction is dramatically increasing, but continues to have a dismal prognosis. Esophagectomy provides the best opportunity for longterm cure, but is hampered by increased rates of perioperative morbidity.. We reviewed our large institutional experience to evaluate the impact of postoperative complications on the long-term survival of patients undergoing resection for curative intent.

Methods: We identified 237 patients who underwent esophagogastrectomy, with curative intent, for cancer between 1994 and 2008. Complications were graded using the previously published Clavien scale. Survival was calculated using Kaplan-Meier methodology and survival curves were compared using log-rank tests. Mulivariate analysis was performed with continuous and categorical variables as predictors of survival, and examined with logistic regression and odds ratio confidence intervals.

Results: There were twelve (5\%) perioperative deaths. The average age of all patients was 62 , and the majority $(82 \%)$ was male. Complication grade did not significantly affect long-term survival, although patients with grade IV (serious) complications did have a decreased survival $(\mathrm{p}=0.15)$. Predictors of survival showed that the minimally invasive type esophagectomy $(\mathrm{p}=0.0004)$ and pathologic stage $(\mathrm{p}=0.0007)$ were determining factors. There was a significant difference in overall survival among patients who experienced pneumonia $(\mathrm{p}=.00016)$ and respiratory complications $(\mathrm{p}=.00040)$, but this was not significant on multivariate analysis.

Conclusion: In this single institution series, we found that major perioperative morbidity did not have a negative impact on long-term survival which is different than previous series. The impact of tumor characteristics at time of resection on long-term survival is of most importance. 


\section{INTRODUCTION}

Esophageal cancer is a devastating disease with a grim prognosis. The National Cancer Institute's Surveillance Epidemiology and End Results (SEER) reports 5-year survival rates for localized esophageal cancer to be $37.4 \%$, regional to be $18.8 \%$, and distant to be $3.2 \%{ }^{1}$ Surgery remains the treatment of choice for prolonged survival and the chance for a definitive cure. However, esophagectomy is a complicated procedure often associated with increased risks of postoperative morbidity and mortality.

Known factors that improve postoperative prognosis are early stage at resection, R0 resection and complete response to neoadjuvant chemoradiotherapy. However, there is still debate on the impact of postoperative complications and associated morbidity on long-term survival. In 2004, a retrospective analysis of 510 patients who underwent esophagogastrectomy for esophagus or gastroesophageal junction carcinoma at Memorial Sloan-Kettering Cancer Center $^{2}$ reported that patients with no technical complications had better overall survival than patients with technical complications. A 2009 retrospective analysis of 150 patients who underwent transthoracic esophagectomy for curative intent at Leuven University Hospitals ${ }^{3}$ reported a strong correlation between severity of complications and time to tumor recurrence. A 2008 retrospective analysis by Lagarde et al, of 191 patients, who died from tumor recurrence ${ }^{4}$ concluded that postoperative complications are independently associated with a shorter time interval to death due to recurrence.

On the other hand, in 2006, a retrospective analysis of 522 patients who underwent resection of thoracic esophagus and gastroesophageal carcinoma at Veneto Region's Center for Esophageal Diseases ${ }^{5}$ reported that long term prognosis is dependent exclusively on the tumor characteristics and not affected by surgical complications. Similarly, a 2006 retrospective 
analysis of 434 patients who underwent resection of squamous cell carcinoma of the esophagus at University of Hong Kong Medical Centre ${ }^{6}$ reported no effect on long term survival in patients with surgical complications.

There are also conflicting reports on the effect of respiratory complications, the most common being pneumonia, on long-term prognosis. Examining 38 patients who developed pneumonia amongst 118 patients total, a 2004 study ${ }^{7}$ reported that pneumonia not only affected perioperative mortality, but also long term survival. This is in contrast with a study in $2011^{8}$, which did not find any significant difference in disease free survival as a result of respiratory complications of atelectasis, pneumonia, or acute respiratory distress syndrome.

To further examine this important question, we reviewed our large single-institution experience to determine the impact of perioperative complications on long-term survival in patients with cancers of the esophagus and GE junction who have undergone esophagectomy. 


\section{PATIENTS AND METHODS}

Using an IRB-approved institutional esophagectomy database, we identified patients who underwent esophagectomy for invasive adenocarcinoma or squamous cell carcinoma of the esophagus, gastroesophageal junction, or stomach cardia at Thomas Jefferson University Hospital (TJUH) between January 1994 and December 2008. There were 237 patients who had undergone surgery with curative intent. In many cases, we performed a retrospective review of the medical records of patients in order to retrieve specific data such as neo-adjuvant treatments, surgical data, histologic and pathologic data of the resected specimen, postoperative surgical and medical complications, adjuvant therapy, recurrence, and survival.

\section{Operative procedure}

The type of esophageal resection was assigned according to the operative note and was performed at discretion of the operating surgeon. The type of esophagectomy performed included: Ivor-Lewis (laparotomy and right thoracotomy), transhiatal (laparotomy and neck incision), 3-hole (laparotomy, thoracotomy, and neck incision), and minimally invasive esophagectomy (MIE), which includes laparoscopy and video-assisted thoracoscopy (VATS), laparoscopic transhiatal, and thoracoscopic 3-hole.

\section{Pathology}

All patients had squamous cell carcinoma or adenocarcinoma of the esophagus, gastroesophageal junction, or gastric cardia. Patients were staged according to the $6^{\text {th }}$ Edition of the AJCC staging system ${ }^{9}$. Resections were defined as: complete removal of tumor with microscopic examination of margins showing no tumor cells (R0), microscopic examination of margins showing tumor cells (R1), and macroscopic examination of margins showing tumor cells (R2). Patients who underwent $\mathrm{R} 2$ resection (non-curative intent) were eliminated from 
survival analysis. A pathologic complete response (pCR) was defined as a patient who did not have any viable tumor in the specimen at the time of surgical resection.

\section{Complications}

We graded postoperative technical and medical complications related to the operation using a modification of the Clavien classification ${ }^{10}$. Complications were classified into 6 grades (Table 1). In brief, Grade 0 patients did not experience any complications. Grade 1 was assigned to patients who experienced complications that did not result in a change of the postoperative course. Complications that required pharmacological treatment, blood transfusion, or total parenteral nutrition were assigned Grade 2. Any complication that required invasive or radiological intervention was assigned Grade 3, Patients who experienced life-threatening complications requiring ICU stay were given a Grade 4 complication - 4a for single organ dysfunction and $4 \mathrm{~b}$ for multi-organ dysfunction. Perioperative mortality was assigned Grade 5. Perioperative complications and morbidity were recorded during the initial hospital stay - from day of surgery to discharge. Complications resulting in patients being readmitted within 30 days of surgery were also considered. Perioperative mortality was considered to include any patient who died within 90 days of surgery or during the postoperative stay for their esophagectomy. Survival and Statistical Analysis

Survival data were obtained from the medical records and the Social Security Death Index. Survival (months) was calculated from the date of surgery. Patients were followed for survival for at least one year post-operation. Survival analysis was calculated using KaplanMeier methodology and curves were compared using log-rank tests. Continuous variables (length of stay) were compared using Student's t-test, with a $\mathrm{p}$ value $<0.05$ being considered significant. Categorical variables were compared using chi-square. A multivariate analysis was performed 
with continuous and categorical variables as predictors of survival, and examined with logistic regression and odds ratio confidence intervals. The following complications were included in the multivariate analysis - pneumonia, respiratory failure, anastomotic leakage, and wound infection. 


\section{RESULTS}

\section{Patient characteristics}

We identified all patients who underwent an operation with curative intent for invasive squamous cell carcinoma or adenocarcinoma $(n=237)$. The average age of patients was 62 (range 32-86). The majority of patients were men ( $82.3 \%$ versus $17.7 \%, \mathrm{M} / \mathrm{F} 4.6: 1)$. There were 140 (59.1\%) patients that were nonsmokers, while 97 (40.9\%) had an active smoking history. The majority of patients received neoadjuvant chemoradiation treatment $(n=155,65.4 \%)$, predominantly 5-fluorouracil and cisplatinum with 45Gy external beam radiation. Out of the 155 patients who received neoadjuvant treatment, 33 (21.3\%) patients had a pCR. Of the 237 procedures (Table 2), the most common were transhiatal $(n=110,46.4 \%)$ and Ivor-Lewis $(n=58$, $24.5 \%)$. There were also $26(11.0 \%)$ were minimally invasive esophagectomy procedures. Adenocarcinoma was present in 201 tumors (84.8\%). The median length of postoperative stay (LOS) was 12 days (range 1-116).

Negative margin resection was achieved in 212 patients (89.5\%), and R1 resection in 16 patients $(6.8 \%)$. The majority of tumors (Table 2) were located at the gastroesophageal junction $(\mathrm{n}=106,44.7 \%)$ and distal esophagus $(\mathrm{n}=80,33.8 \%)$. The most frequent pathologic stage was stage II $(\mathrm{n}=84,35.4 \%)$.

\section{Postoperative Complications (Table 3)}

There were $100(42.2 \%)$ patients who had an unremarkable postoperative course (complication grade 0). Twelve patients (5.1\%) had perioperative mortalities (Grade 5). The majority, 57.8\% ( $\mathrm{n}=137)$ of patients had postoperative complications (Grades 1-4). Among patients with complications, $9.6 \%(\mathrm{n}=12)$ were Grade 1, 42.4\% ( $\mathrm{n}=53)$ were Grade 2, $20 \%$ 
$(n=25)$ were Grade 3, and $28 \%(n=35)$ were Grade 4 . The median survival among the 225 patients (excluding 12 patients with perioperative mortalities) was 20.8 months.

Patients were divided into three classes, those with no complications (Group 1-Grade 0, $\mathrm{n}=99,42.0 \%$ ), those with minor complications (Group 2-Grade 1-2, n=65, 27.5\%), and those with major complications and mortality (Group 3-Grades 3-5, n=72, 30.5\%). Patient characteristics (age, gender, smoking history, histology, tumor location, pathologic stage, induction therapy, operative procedures) between the two groups were not found to be significantly different (Table 4). There was no significant difference in completeness of resection between the two groups. However, the median LOS $(\mathrm{p}<0.0001)$ was found to be significantly different between patients in Group 1 (12 days), Group 2 (13.1 days), and Group 3 (29 days).

The most common complications (Table 5) were respiratory failure requiring intubation $(n=35,14.8 \%)$, supraventricular arrhythmia $(n=34,14.3 \%)$, anastomotic leakage $(n=32,13.5 \%)$, pleural effusion requiring thoracocentesis or a chest tube $(n=30,12.7 \%)$, wound infection $(n=27$, $11.4 \%)$, and pneumonia $(\mathrm{n}=26,11 \%)$.

Overall survival (Figure 1) was compared for patients with no (grade 0), minor complications (Grade 1,2) and major complications and mortality (Grade 3, 4 and 5). There was not a significant difference in overall survival by complication grade $(\mathrm{p}=0.095)$, even though patients with major complications did fare slightly worse (especially in the first 5 years). In the bivariate analysis, the survival was worst for patients with grade 4 complications, however this was not statistically significant $(\mathrm{p}=0.15)$.

However, when examining specific complications (Table 6), we found a significant increase in length of stay for patients who had postoperative pneumonia, respiratory failure, or anastomotic leakage. There was a significant difference in overall survival $(\mathrm{p}=0.0002)$ among 
patients who developed pneumonia ( $\mathrm{n}=26,15.0$ months) and patients who did not $(\mathrm{n}=210,27.8$ months), as well as among patients who developed respiratory failure ( $\mathrm{n}=42,15.8$ months) and patients who did not $(\mathrm{n}=194,28.7$ months). The impact of pneumonia $(\mathrm{p}=0.24)$ and respiratory failure $(\mathrm{p}=0.15)$ was lost on multivariate analysis as a predictor of survival. Multivariable analysis (Table 7) on the predictors of survival showed that type of esophagectomy $(p=0.0004)$ and pathologic stage $(\mathrm{p}=0.0007)$ were determining factors. Patients who underwent an IvorLewis esophagectomy had a higher risk for death $(\mathrm{p}=0.0079)$, while patients who had a MIE had a lower risk for death $(\mathrm{p}=0.005)$. As the pathologic stage increases, so does risk of death, particularly among patients with stage II $(\mathrm{p}=0.0078)$ and III $(\mathrm{p}=0.0002)$ esophageal cancers. 


\section{DISCUSSION}

Esophageal resection is a complicated procedure associated with increased morbidities and mortality. However, there is still a debate of the impact of postoperative complications and its impact on prognosis and survival. We observed that patients whose postoperative periods were unremarkable or had minor complications (Grades $0,1-2$ ) had shorter lengths of stay, but no significant difference in survival compared with patients with major morbidities (Grades 3-5). This study shows that one of the most important and independent predictor of survival is pathologic stage, with Stage II and III tumors associated with a significantly higher risk of death. These results agree with those reported by Ferri and colleagues, as well as Ancona and colleagues at Veneto Region's Center for Esophageal Diseases, who concluded that surgical complications play no role on long-term prognosis, which is entirely dependent on pathology and tumor characteristics ${ }^{3}$.

Major perioperative morbidities may not have a significant effect on long-term survival due to the high-volume of esophagectomys performed at our institution (Figure 2). TJUH is a high volume institution and National Cancer Institute designated cancer center with a multidisciplinary approach, employing standardized clinical pathways to treating patients undergoing major surgeries. Finlayson and colleagues ${ }^{11}$ reported an $8.5 \%$ higher difference in mortality rate, particularly among older patients, in low volume centers compared to high volume centers. When comparing the trend in referrals to high volume institutions resulting in a concentration of major procedures in a smaller number of hospitals from 1999-2008, Finks and colleagues $^{12}$ found a significant $11 \%$ decrease in operative mortality among esophagectomy patients. The experience of not only the surgical team, but also the nursing and ICU staff may benefit in detecting and treating postoperative complications efficiently and effectively, reducing 
its severity. Ghaferi and colleagues ${ }^{13}$ at the University of Michigan attributed the "failure to rescue" (defined as fatalities among patients with complications) in high-risk surgeries such as esophagectomy as a principal factor, demonstrating that although low volume centers have a slightly higher overall complication rate, they also have a significantly higher failure to rescue rate of $30.3 \%$, compared to $13.1 \%$ in high volume centers. Advancements in addressing postoperative complications with procedures such as endoscopic stenting for anastomotic leak, which are more readily available at specialized institutions, may also contribute to a decrease in operative mortality ${ }^{14,15}$. What we observed in this single institution review may not be applicable to most hospitals.

Furthermore, the use of the modified Clavien classification to grade postoperative complications in a major surgery such as esophagectomy may not be reliable. For example, complications such as transient confusion are graded similar to wound infections as Grade 1. However, it has been reported that postoperative infections do have a negative impact on longterm survival in major gastro-intestinal cancer resections ${ }^{16,17}$. In a study conducted by Lerut and colleagues on the impact of postoperative complications after transthoracic esophagectomy using the modified Clavien classification, similar results were reported that there was no difference in survival curves between grades 2,3 , and 4 complications ${ }^{5}$. Using a generalized grading system may dilute the real impact of specific complications in patients who undergo esophagectomy. It may be necessary to devise a separate and unique postoperative classification system for this type of major surgery.

Analysis of the impact of specific complications found that wound infection, anastomotic leak, and severe respiratory morbidities (Adult Respiratory Distress Syndrome, respiratory failure, ventilatory support $>48$ hours) did not significantly affect survival, although there was a 
significant difference in overall survival among patients who did experience pneumonia versus patients who did not. These results agree with D'Annoville et al, who found that technical complications were associated with worse immediate hospital outcomes, but did not affect longterm survival ${ }^{8}$. In addition, major postoperative morbidities were found to significantly increase patient LOS. A recent study in Bangalore, India with a study population $(n=236)$ similar to ours, reported that anastomotic leak, delayed wound healing, and postoperative weight loss increased the risk of relapse ${ }^{18}$. This may have to do with a release in cytokines (Interleukin (IL)-6, IL-8, IL-1, tumor necrosis factor $\alpha$ ) in response to stress, with the resulting inflammation associated with infection causing a hormonal milieu more conducive to the re-growth of cancer cells, known as "inflammatory oncotaxis" 19,20 . Further research on whether or not the significant increase in patient LOS as a result of major postoperative complications has an effect on relapsefree survival is needed.

In conclusion, esophagectomy is a major invasive procedure that can be performed safely at high volume centers. Although the procedure is associated with potential postoperative morbidities, postoperative complication rates are reasonable when performed and cared for by an experienced medical team. The impact of major postoperative complications on long-term survival may not be as consequential as previously reported, with instead tumor characteristics at time of resection of most importance. 


\section{REFERENCES}

1. Altekruse SF, Kosary CL, Krapcho M, et al (eds). SEER Cancer Statistics Review, 1975-2007, National Cancer Institute. Bethesda, Mhttp://seer.cancer.gov/csr/1975_2007/, based on November 2009 SEER data submission, posted to the SEER web site, 2010. 2. Rizk NP, Bach PB, Schrag D, et al. The impact of complications on outcomes after resection for esophageal and gastroesophageal junction carcinoma. J Am Coll Surg 2004; 198:42-50. 3. Lerut T, Moons J, Coosemans W, et al. Postoperative Complications After Transthoracic Esophagectomy for Cancer of the Esophagus and Gastroesophageal Junction Are Correlated With Early Cancer Recurrence. Ann Surg 2009; 250(5):798-807.

4. Lagarde S, Reitsma J, Maris A, et al. Preoperative prediction of the occurrence and severity of complications after esophagectomy for cancer with use of nomogram. Ann Thorac Surg 2008; 85:1938-1946.

5. Ancona E, Cagol M, Epifani M, et al. Surgical complications do not affect longterm survival after esophagectomy for carcinoma of the thoracic esophagus and cardia. J Am Coll Surg 2006; 203:661-669.

6. Ferri LE, Law S, Wong KH, et al. The influence of technical complications on postoperative outcome and survival after esophagectomy. Ann Surg Oncol 2006; 13(4):557-564.

7. Kinugasa S, Tachibana M, Yoshimura H, et al. Postoperative pulmonary complications are associated with worse short- and long-term outcomes after extended esophagectomy. J Surg Oncol 2004; 88:71-77.

8. D'Annoville T, D'Journo XB, Trousse D, et al. Respiratory complications after oesophagectomy for cancer do not affect disease-free survival. Eur J Cardiothoracic Surg 2012; 41(5):e66-73. 
9. AJCC Cancer Staging Manual/American Joint Committee on Cancer, 6th ed., New York: Springer-Verlag, 2002.

10. Dindo D, Demartines N, Clavien PA. Classification of Surgical Complications: A New Proposal With Evaluation in a Cohort of 6336 Patients and Results of a Survey. Ann Surg 2004; 240:205-213.

11. Finlayson EV, Goodney PP, Birkmeyer JD. Hospital Volume and Operative Mortality in Cancer Surgery: A National Study. Arch Surg 2003; 138:721-725.

12. Finks JF, Osborne NH, Birkmeyer JD. Trends in Hospital Volume and Operative Mortality for High-Risk Surgery. N Engl J Med 2011; 364:2128-2137.

13. Ghaferi AA, Birkmeyer JD, Dimick JB. Hospital Volume and Failure to Rescue With Highrisk Surgery. Med Care 2011; 49(12):1076-1081.

14. D'Cunha J, Rueth NM, Groth SS, et al. Esophageal stents for anastomotic leaks and perforations. J Thorac Cardiovasc Surg 2011; 142(1): 39-46.

15. Freeman RK, Vyverberg A, Ascioti AJ. Esophageal stent placement for the treatment of acute intrathoracic anastomotic leak after esophagectomy. Ann Thorac Surg 2011; 92(1): 204208

16. Hirai T, Yamashita Y, Mukaida H, et al. Poor prognosis in esophageal cancer patients with postoperative complications. Surg Today 1998; 28:576-579.

17. Tsujimoto H, Ichikura T, Ono S, et al. Impact of Postoperative Infection on Long-Term Survival After Potentially Curative Resection for Gastric Cancer. Ann Surg Oncol 2009; 16:311318. 
18. Attili VSS, Bapsy PP, Ramachandra C, et al. Influence of Postoperative Complications on Relapse-Free Survival in Gastrointestinal Malignancies. Gastrointest Cancer Res 2009; 3(5):179182.

19. DerHagopian RP, Sugarbaker EV, Ketcham A, et al. Inflammatory oncotaxis. JAMA 1978; 240:374-375.

20. Van Zee KJ, Deforge LE, Fisher E, et al. IL-8 in septic shock, endotoxemia, and after IL-1 administration. J Ummunol 1991; 146:3478-3482. 
TABLES

Table 1-Clavien complication scale

\begin{tabular}{|l|l|}
\hline Grade & Definition \\
\hline 0 & No Complications \\
\hline 1 & $\begin{array}{l}\text { Deviation from normal postoperative course without need for medical } \\
\text { or surgical intervention }\end{array}$ \\
\hline 2 & $\begin{array}{l}\text { Complications requiring pharmacological treatment, transfusion, or } \\
\text { total parenteral nutrition }\end{array}$ \\
\hline 3 & $\begin{array}{l}\text { Complications requiring invasive or radiological intervention: } \\
3 \mathrm{a}-\text { does not require general anesthesia }\end{array}$ \\
\hline 4 & $\begin{array}{l}\text { Life-threatening complications requiring intensive care unit } \\
\text { management: } \\
4 \mathrm{a}-\text { single-organ dysfunction } \\
4 \mathrm{~b}-\text { multi-organ dysfunction }\end{array}$ \\
\hline 5 & \begin{tabular}{l} 
Death \\
\hline
\end{tabular} \\
\hline
\end{tabular}


Table 2. Patient Characteristics

\begin{tabular}{|c|c|c|}
\hline Characteristics & $\mathbf{N}$ & $\%$ \\
\hline Total & 237 & \\
\hline Age (mean) & 62 (range 32-86) & \\
\hline Gender, male & 195 & $82.3 \%$ \\
\hline Smoker & 97 & $40.9 \%$ \\
\hline Induction Chemoradiation & 155 & $65.4 \%$ \\
\hline \multicolumn{3}{|l|}{ Procedure } \\
\hline Transhiatal & 110 & $46.4 \%$ \\
\hline Ivor-Lewis & 58 & $24.5 \%$ \\
\hline 3-Hole & 42 & $17.7 \%$ \\
\hline MIE & 26 & $11.0 \%$ \\
\hline \multicolumn{3}{|l|}{ Histology } \\
\hline Adenocarcinoma & 201 & $84.8 \%$ \\
\hline Squamous cell carcinoma & 36 & $15.2 \%$ \\
\hline \multicolumn{3}{|l|}{ Tumor Location } \\
\hline Proximal 1/3 & 5 & $2.1 \%$ \\
\hline Middle $1 / 3$ & 17 & $7.2 \%$ \\
\hline Distal 1/3 & 80 & $33.8 \%$ \\
\hline GE Junction & 106 & $44.7 \%$ \\
\hline Stomach cardia & 29 & $12.2 \%$ \\
\hline \multicolumn{3}{|l|}{ Pathologic Stage } \\
\hline 0 & 39 & $16.5 \%$ \\
\hline
\end{tabular}




\begin{tabular}{|c|l|l|} 
I & 51 & $21.5 \%$ \\
\hline II & 84 & $35.4 \%$ \\
\hline III & 52 & $21.9 \%$ \\
\hline IV & 11 & $4.7 \%$ \\
\hline R0 & 212 & $89.5 \%$ \\
\hline
\end{tabular}

MIE—Minimally Invasive Esophagectomy 
Table 3. Complication Grade Breakdown

\begin{tabular}{|l|l|l|}
\hline Grade & $\mathbf{n}$ & $\%$ \\
\hline 0 & 100 & 42.2 \\
\hline I & 12 & 5.1 \\
\hline II & 53 & 22.4 \\
\hline III & 25 & 10.5 \\
\hline IV & 35 & 14.7 \\
\hline V & 12 & 5.1 \\
\hline
\end{tabular}


Table 4. Complication Grades

\begin{tabular}{|c|c|c|c|c|}
\hline & None (Grade 0) & Minor (Grades 1-2) & Major/Mortality (Grades 3-5) & p-value \\
\hline Number & 99 & 65 & 72 & \\
\hline Age (mean) & 60.1 & 62.2 & 63.1 & 0.16 \\
\hline Gender & & & & 0.18 \\
\hline Male & $76(76.8)$ & $56(86.2)$ & $62(86.1)$ & \\
\hline Female & $23(23.2)$ & $9(13.8)$ & $10(13.9)$ & \\
\hline Smoker & & & & 0.55 \\
\hline No & $58(58.6)$ & $42(64.6)$ & $40(55.6)$ & \\
\hline Yes & $41(41.1)$ & $23(35.4)$ & $32(44.4)$ & \\
\hline Histology & & & & 0.91 \\
\hline Adenocarcinoma & $83(83.8)$ & $57(87.7)$ & $61(84.7)$ & \\
\hline $\begin{array}{l}\text { Squamous cell } \\
\text { carcinoma }\end{array}$ & $16(16.2)$ & $9(12.3)$ & $11(15.3)$ & \\
\hline Tumor Location & & & & 0.55 \\
\hline Proximal $1 / 3$ & $2(2.0)$ & $1(1.6)$ & $2(2.8)$ & \\
\hline Middle $1 / 3$ & $9(9.1)$ & $5(7.7)$ & $3(4.2)$ & \\
\hline Distal 1/3 & $34(34.3)$ & 19 (29.2) & $27(37.5)$ & \\
\hline GE Junction & $38(38.4)$ & $35(53.8)$ & $32(44.4)$ & \\
\hline Stomach Cardia & $16(16.2)$ & $5(7.7)$ & $8(11.1)$ & \\
\hline Pathologic Stage & & & & 0.73 \\
\hline 0 & $15(15.2)$ & $12(18.5)$ & $11(15.3)$ & \\
\hline $\mathrm{I}$ & $20(20.2)$ & $13(20.0)$ & $18(25.0)$ & \\
\hline II & $33(33.3)$ & $27(41.5)$ & $24(33.3)$ & \\
\hline III & $27(27.3)$ & $11(16.9)$ & $14(19.4)$ & \\
\hline
\end{tabular}




\begin{tabular}{|c|c|c|c|c|}
\hline IV & $4(4.0)$ & $2(3.1)$ & $5(6.9)$ & \\
\hline \multicolumn{5}{|l|}{ Induction Therapy } \\
\hline CRT & $67(67.7)$ & $41(63.1)$ & $46(63.9)$ & 0.80 \\
\hline $\mathrm{pCR}$ & $15(15.2)$ & $9(13.8)$ & $9(12.5)$ & 0.88 \\
\hline Procedure & & & & 0.16 \\
\hline Transhiatal & $43(43.4)$ & $39(60.0)$ & $28(38.9)$ & \\
\hline Ivor-Lewis & $28(28.3)$ & $12(18.5)$ & $17(23.6)$ & \\
\hline 3-Hole & $15(15.2)$ & $9(13.8)$ & $18(25.0)$ & \\
\hline MIE & $13(13.1)$ & $5(7.7)$ & $8(11.1)$ & \\
\hline \multicolumn{5}{|l|}{ LOS (day) } \\
\hline Mean & 12.0 & 13.1 & 29 & $<0.0001$ \\
\hline Median & 10 & 12 & 20.5 & \\
\hline Resection & & & & 0.43 \\
\hline R0 & $86(86.9)$ & $60(92.3)$ & $66(91.7)$ & \\
\hline $\mathrm{R} 1$ & $7(7.1)$ & $4(6.2)$ & $5(6.9)$ & \\
\hline Unknown & $6(6.0)$ & $1(1.5)$ & $1(1.4)$ & \\
\hline Mean Survival (months) & 28.0 & 29.8 & 21.1 & 0.08 \\
\hline
\end{tabular}

pCR—pathologic complete response

CRT-chemoradiation therapy

MIE-minimally invasive esophagectomy

LOS—length of stay 
Table 5. Complication breakdown

\begin{tabular}{|l|l|l|}
\hline Complication & $\mathbf{n}$ & Grade \\
\hline $\begin{array}{l}\text { Respiratory Failure (requiring } \\
\text { intubation) }\end{array}$ & $35(14.8)$ & 4 \\
\hline Supraventricular Arrhythmia & $34(14.3)$ & 2 \\
\hline Anastomotic Leakage & $32(13.5)$ & 2 \\
\hline Pleural Effusion (requiring & & \\
thoracentisis or chest tube) & $30(12.7)$ & $3 a$ \\
\hline Wound infection & $27(11.4)$ & 1 \\
\hline Pneumonia & $26(11.0)$ & 2 \\
\hline Re-operation & $25(10.5)$ & $3 b$ \\
\hline Bacteremia & $21(8.9)$ & 2 \\
\hline Deep Venous Thrombosis & $12(5.1)$ & 2 \\
\hline Ventilatory Support $>48$ hours & $18(7.6)$ & 2 \\
\hline Adult Respiratory Distress & $14(5.9)$ & 2 \\
\hline Syndrome & $12(5.1)$ & 5 \\
\hline Perioperative Mortality & & \\
\hline
\end{tabular}


Table 6. Specific Complications

\begin{tabular}{|c|c|c|c|c|c|c|c|c|}
\hline & \multicolumn{2}{|c|}{ Pneumonia } & \multicolumn{2}{|c|}{$\begin{array}{c}\text { Respiratory } \\
\text { Failure/ARDS/ } \\
\text { Ventilatory Support }\end{array}$} & \multicolumn{2}{|c|}{ Wound infection } & \multicolumn{2}{|c|}{ Anastomotic Leak } \\
\hline & $\mathbf{n}$ & $\%$ & $\mathbf{n}$ & $\%$ & $\mathbf{n}$ & $\%$ & $\mathbf{n}$ & $\%$ \\
\hline Number & 26 & 11.0 & 42 & 17.8 & 27 & 11.4 & 32 & 14.3 \\
\hline Mean LOS (days) & \multicolumn{2}{|c|}{35.2} & \multicolumn{2}{|c|}{37.0} & \multicolumn{2}{|c|}{22.6} & \multicolumn{2}{|c|}{24.7} \\
\hline p Value & \multicolumn{2}{|c|}{0.0018} & \multicolumn{2}{|c|}{$<0.0001$} & \multicolumn{2}{|c|}{0.14} & \multicolumn{2}{|c|}{0.015} \\
\hline Mean Survival (months) & \multicolumn{2}{|c|}{15.0} & \multicolumn{2}{|c|}{15.8} & \multicolumn{2}{|c|}{21.5} & \multicolumn{2}{|c|}{27.2} \\
\hline p Value & \multicolumn{2}{|c|}{0.00016} & \multicolumn{2}{|c|}{0.00040} & \multicolumn{2}{|c|}{0.17} & \multicolumn{2}{|c|}{0.88} \\
\hline
\end{tabular}


Table 7. Multivariable Predictors of Death after Esophagectomy

\begin{tabular}{|c|c|c|c|}
\hline Predictor & Risk ratio & $95 \% \mathrm{Cl}$ & p-value \\
\hline Age & & & 0.18 \\
\hline $31-54$ & 1.00 & * & \\
\hline $55-60$ & 0.51 & $0.20-1.30$ & \\
\hline $61-69$ & 0.39 & $0.15-1.01$ & \\
\hline $70-86$ & 0.86 & $0.33-2.33$ & \\
\hline Gender (female) & 1.19 & $0.50-2.85$ & 0.69 \\
\hline Tumor Location & & & 0.93 \\
\hline GE Junction & 1.00 & * & \\
\hline Proximal and Middle $1 / 3$ & 0.85 & $0.20-3.62$ & \\
\hline Distal $1 / 3$ & 1.17 & $0.53-2.61$ & \\
\hline Cardia & 1.34 & $0.35-5.12$ & \\
\hline Type of Esophagectomy & & & 0.0004 \\
\hline Transhiatal & 1.00 & * & \\
\hline 3-Hole & 0.55 & $0.22-1.41$ & \\
\hline Ivor-Lewis & 3.56 & $1.40-9.08$ & \\
\hline MIE & 0.17 & $0.05-0.59$ & \\
\hline Pathologic Stage & & & 0.0007 \\
\hline 0 & 1.00 & * & \\
\hline 1 & 1.49 & $0.50-4.42$ & \\
\hline 2 & 3.71 & $1.41-9.74$ & \\
\hline 3 & 11.98 & $3.25-44.19$ & \\
\hline 4 & 6.38 & $0.94-43.29$ & \\
\hline Histology (Adenocarcinoma) & 1.40 & $0.47-4.23$ & 0.55 \\
\hline Complication Grade & & & 0.84 \\
\hline
\end{tabular}




\begin{tabular}{|l|c|c|c|}
\hline 0 & 1.00 & $*$ & \\
\hline I & 1.26 & $0.25-6.40$ & \\
\hline II & 0.57 & $0.23-1.41$ & \\
\hline III & 1.05 & $0.34-3.18$ & \\
\hline IV & 0.73 & $0.14-3.77$ & \\
\hline V & $>999.99$ & $<0.001->999.99$ & \\
\hline Specific Complication & & & \\
\hline Pneumonia & 2.19 & $0.59-8.11$ & 0.24 \\
\hline Respiratory Failure/ARDS/Ventilatory Support & 3.31 & $0.64-17.10$ & 0.15 \\
\hline Wound Infection & 1.16 & $0.33-4.11$ & 0.82 \\
\hline Anastomotic Leak & 1.09 & $0.33-3.57$ & 0.89 \\
\hline
\end{tabular}

*Reference group. 
Figure 1. Kaplan-Meier analysis of survival by complication

grades

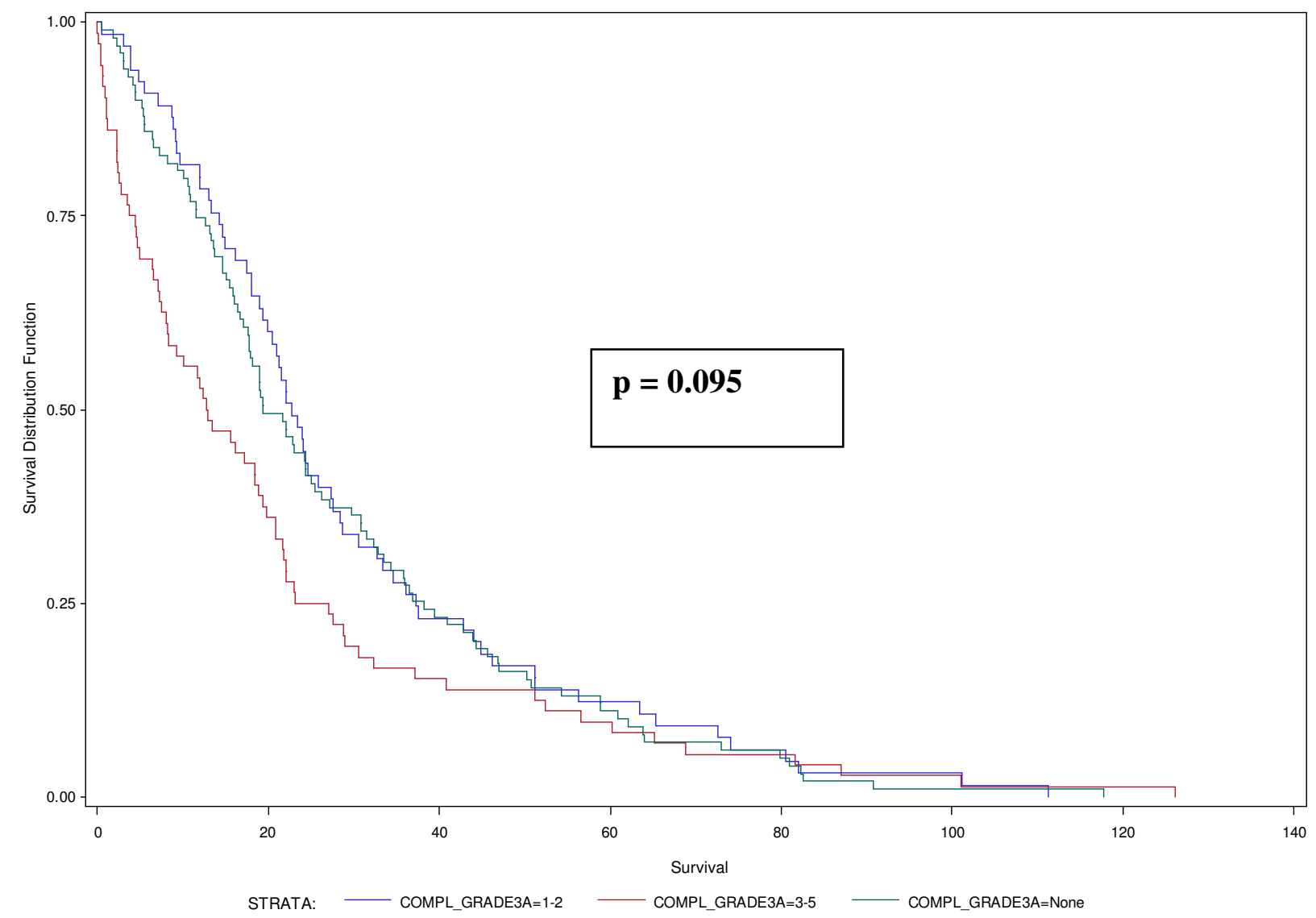

Figure Legend: Kaplan-Meier survival curve demonstrating overall survival of patients with esophageal cancer undergoing esophagectomy broken down by types of complications where the green line indicates patients who experienced no postoperative complications (Clavien Grade 0), the blue line indicates patients who experienced minor postoperative complications (Clavien Grade 1 and 2), and the red line indicates patients who experienced major postoperative complications or mortality (Clavien Grade 3, 4, and 5). 
Figure 2. Frequency of esophagectomies by year

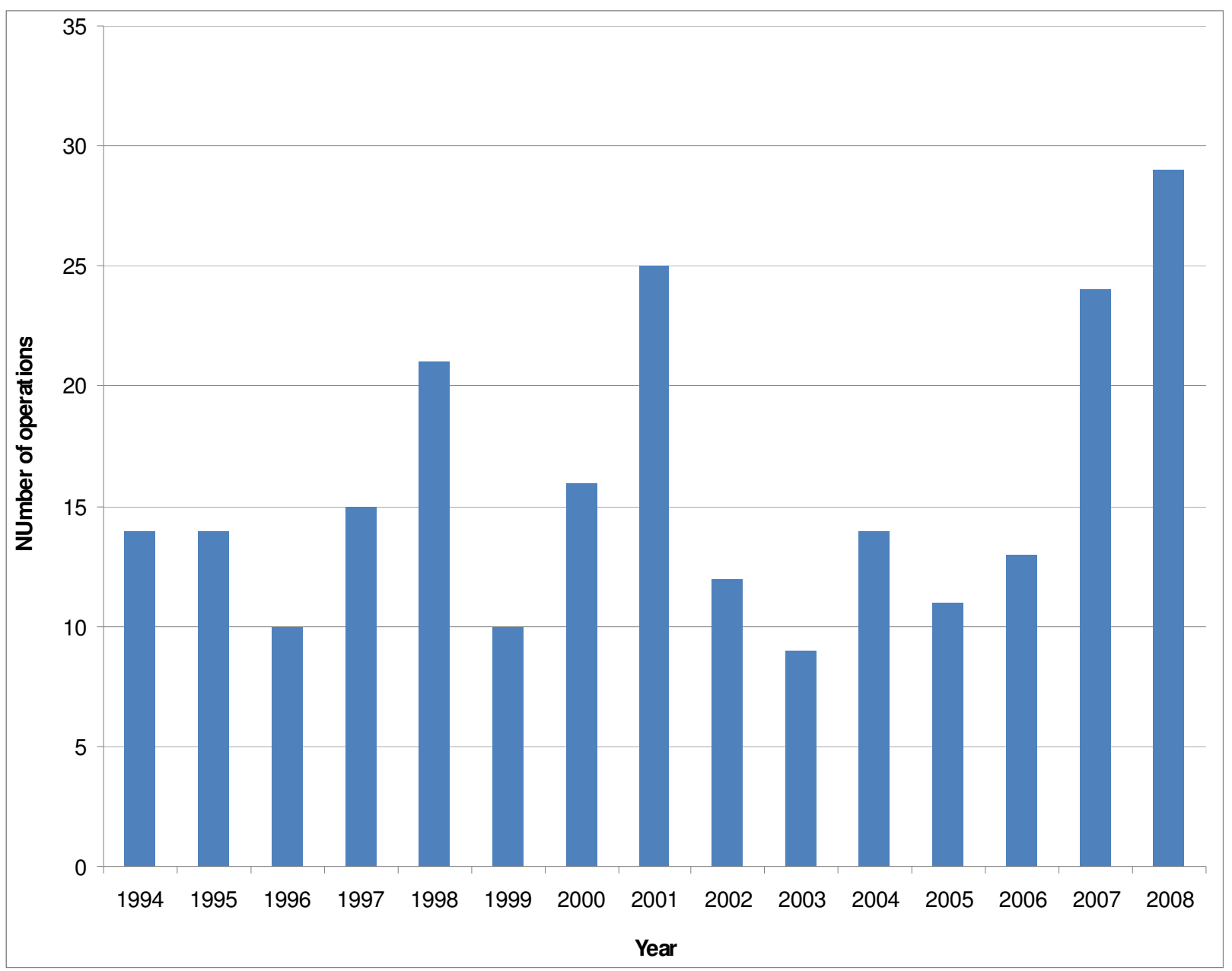

Figure Legend: Histogram demonstrating the number of esophageal resections for curative intent performed at Thomas Jefferson University Hospitals from 1994-2008. 